\title{
Research on Application of Regression Least Squares Support Vector Machine on Performance Prediction of Hydraulic Excavator
}

\author{
Zhan-bo Chen ${ }^{1,2}$ \\ ${ }^{1}$ Zhongnan University of Economics and Law, Wuhan 430074, China \\ ${ }^{2}$ Hubei University of Economics, Wuhan 430205, China \\ Correspondence should be addressed to Zhan-bo Chen; chenzhanbo2014@163.com \\ Received 15 July 2014; Revised 11 October 2014; Accepted 22 October 2014; Published 11 November 2014 \\ Academic Editor: Onur Toker \\ Copyright (C) 2014 Zhan-bo Chen. This is an open access article distributed under the Creative Commons Attribution License, \\ which permits unrestricted use, distribution, and reproduction in any medium, provided the original work is properly cited.

\begin{abstract}
In order to improve the performance prediction accuracy of hydraulic excavator, the regression least squares support vector machine is applied. First, the mathematical model of the regression least squares support vector machine is studied, and then the algorithm of the regression least squares support vector machine is designed. Finally, the performance prediction simulation of hydraulic excavator based on regression least squares support vector machine is carried out, and simulation results show that this method can predict the performance changing rules of hydraulic excavator correctly.
\end{abstract}

\section{Introduction}

The hydraulic excavator belongs to the construction machinery, which has been applied in many fields successfully, such as transportation industry, mining industry, construction industry, and hydraulic engineering. The hydraulic excavator is made up of three parts, which are working equipment, upper turntable, and traveling gear. Normally working conditions of the hydraulic excavator are bad, and the loads being applied to the hydraulic excavator are big; therefore, the engine will deviate from operating mode with low fuel consumption, and then hydraulic excavator will exhibit poor performance. In addition, the energy consumption of the hydraulic pressure system is big, which can lead to the big energy wasting. Therefore, it is necessary to predict the performance of the hydraulic excavator correctly, and then the working efficiency of the hydraulic excavator can be improved [1].

The performance predicting procession is nonlinear, which is affected by many uncertain factors; therefore, an effective predicting technology should be chosen. At present, there are many performances prediction methods, such as artificial neural network technology, grey prediction technology, and extension technology [2]. However, the current prediction technologies have some disadvantages: the predicting precision is low, the predicting efficiency is low, and the operation is difficult [2].

Generally, the support vector machine has the nonlinear and uncertain characteristics. In recent years, the support vector machine was established by Vapnik, which has been concerned by many scientists, and the support vector has strong learning ability. Some scientists have improved the support vector machine. The least squares support vector machine is put forward by SukKens. The least squares support machine introduces the least squares system into the support vector, while the traditional support machine applies the two planning methods to deal with function estimation problem; therefore, this method has higher predicting ability than the traditional support machine, which can be applied in the performance prediction of the hydraulic excavator.

\section{Mathematical Model of Least Squares Support Vector Machine}

The support vector machine is a machine learning technology, which is better than artificial neural network technology, grey prediction technology, and extension technology in predicting ability. The support vector machine applies 
to the performance prediction of small samples, and the predicting reliability is good; at the same time, it has good superior ability, and then the high predicting precision can be obtained. Therefore, the good predicting effect can be obtained based on least squares support vector machine for the hydraulic excavator [3].

The training samples $\left\{\left(x_{i}, y_{i}\right)\right\}\left(x_{i}, y_{i} \in R ; i, j=1,2, \ldots\right.$, $n)$ are known, and the least squares support vector machine mainly applies a nonlinear mapping function to make the data transfer to a high dimensional space and then be mapped back to the original space to achieve the linear regression of input space; the linear regression model is shown as follows:

$$
f(x)=[\vec{\omega}, \phi(x)]+b,
$$

where $\omega$ denotes the weighted vector, $\phi(x)$ denotes the mapping function, and $b$ denotes the threshold value.

The regression least squares support vector machine applies two-time penalty function to transfer the regression problem into two-time optimization problem, and the corresponding objective function is expressed as follows:

$$
R_{\text {ref }}[f]=R_{\text {emp }}[f]+\eta\|\psi\|^{2}=\sum_{l=1}^{n} C\left(e_{l}\right)+\eta\|\psi\|^{2},
$$

where $R_{\text {ref }}[f]$ denotes the structural risk, $R_{\text {emp }}[f]$ denotes the empiric risk, $\|\psi\|^{2}$ denotes the confidence risk, $C(\cdot)$ denotes the loss function, $\eta$ denotes regularization factor, $e_{l}=f\left(x_{l}\right)-$ $y_{l}$, and $n$ denotes the sample size.

The $\varepsilon$ insensitive loss function is put forward by Vapnik, which has an insensitive zone that offers any loss value, $\varepsilon$ zone. The information of sample points in $\varepsilon$ zone cannot appear in regression function, and then the regression function is sparse and simple.

The optimal function is constructed based on the idea of $\varepsilon$ insensitive loss function, which is expressed as follows [4]:

$$
\begin{aligned}
& \min _{\omega, b, \tau, \tau^{*}} \quad J=\frac{1}{2} \omega^{T} \omega+C \sum_{i=1}^{n}\left(\tau_{i}+\tau_{i}^{*}\right) \\
& \text { s.t. }\left\{\begin{array}{r}
y_{i}-\omega^{T} \phi\left(x_{i}\right)-b \leq \mu+\tau_{i}, \\
\omega^{T} \phi\left(x_{i}\right)+b-y_{i} \leq \mu+\tau_{i}^{*}, \\
\tau_{i}, \tau_{i}^{*} \geq 0,
\end{array}\right.
\end{aligned}
$$

where $\tau_{i}$ and $\tau_{i}^{*}$ denote the relaxation factors, $C$ denotes the penalty function, $C>0$, and $\mu$ denotes the precision.

The core function is introduced, and the dual function of expression (4) can be expressed as follows [5]:

$$
\begin{gathered}
\max _{\beta, \beta^{*}} \quad J=-\frac{1}{2} \sum_{i, j}^{n}\left(\beta_{i}-\beta_{i}^{*}\right)\left(\beta_{j}-\beta_{j}^{*}\right) \cdot K\left(x_{i}, x_{j}\right) \\
\quad-\mu \sum_{i=1}^{n}\left(\beta_{i}+\beta_{i}^{*}\right)+\sum_{i}^{n} y_{i}\left(\beta_{i}-\beta_{i}^{*}\right) \\
\text { s.t. } \quad \sum_{i=1}^{n}\left(\beta_{i}-\beta_{i}^{*}\right), \quad \beta_{i}, \beta_{i}^{*} \in(0, C],
\end{gathered}
$$

where $\beta_{i}$ and $\beta_{i}^{*}$ are also Lagrange operators and $K\left(x_{i}, x_{j}\right)$ denotes the core function.
The estimating function of the least squares support vector machine can be expressed as follows $[6,7]$ :

$$
f(x)=\sum_{i=1}^{n}\left(\beta_{i}-\beta_{i}^{*}\right) K\left(x, x_{k}\right)+b .
$$

The parameters optimization of the least squares support vector machine is very important. The core function generally applies the radial function. There is an unknown factor $\gamma$, and improving the value of $\gamma$ can improve the convergence rate of the algorithm. In addition, there is another parameter, which is the parameter of the least squares support vector machine $\eta$; the parameters Gamma and $\eta$ can decide the learning ability of the least squares support vector machine together.

\section{Algorithm of the Least Squares Support Vector Machine}

The algorithm procedure of the least squares support vector machine is listed as follows.

Step 1. The range of the two parameters $\gamma$ and $\eta$ is confirmed based on basic principles of the least squares support vector machine, and the empirical range of the two parameters is listed as follows: $\gamma \in[0.01,0.1], \eta \in[0.02,10000]$.

Step 2. The values of the two parameters $\gamma$ and $\eta$ are confirmed in range; then the two-dimensional plane $\left(\gamma_{i}, \eta_{i}\right)$, $i=1,2, \ldots, m ; 1,2, \ldots, n$ can be constructed. The value of Gamma can be chosen according to the real situation of training samples and relating experiences.

Step 3. The pairs of parameters $\left(\gamma_{i}, \eta_{i}\right)$ in different plane grid nodes are input into the least squares support vector machine, the corresponding training is carried out based on training samples, and then the training error is output. $\left(\gamma_{i}, \eta_{i}\right)$ with least error is used as the most optimal results [8].

Step 4. When the training precision of algorithm cannot satisfy the real requirement, the optimal parameter is used as center to construct the new plane grids and confirm the near parameter; then the new training is carried out again; then the precision of the algorithm can be improved, and the procedures mentioned above can be carried out repeatedly; then the multilayers parameter optimization plane network can be formed; finally, the optimal parameters of the least squares support vector machine can be obtained; then the ideal training precision can be obtained [9].

\section{Prediction Simulation of Hydraulic Excavator Based on Least Squares Support Vector Machine}

The prediction model of the hydraulic excavator performance is constructed based on the following basic steps.

(1) The characteristics and performance indexes of the hydraulic excavator are confirmed. And the learning samples of the regression least squares support vector machine are obtained. 
TABLE 1: Data sample of performance prediction for the hydraulic excavator.

\begin{tabular}{lccccccc}
\hline $\begin{array}{l}n_{I C E} \\
\mathrm{r} / \mathrm{min}\end{array}$ & $\begin{array}{c}n_{E M} \\
\mathrm{r} / \mathrm{min}\end{array}$ & $\begin{array}{c}n_{P} \\
\mathrm{r} / \mathrm{min}\end{array}$ & $\begin{array}{c}T_{I C E} \\
\mathrm{~N} \cdot \mathrm{m}\end{array}$ & $\begin{array}{c}T_{E M} \\
\mathrm{~N} \cdot \mathrm{m}\end{array}$ & $\begin{array}{c}T_{P} \\
\mathrm{~N} \cdot \mathrm{m}\end{array}$ & $\begin{array}{c}N_{I C E} \\
\mathrm{~kW}\end{array}$ & $\begin{array}{c}P \\
\mathrm{MPa}\end{array}$ \\
\hline 800 & 800 & 800 & 20 & 15 & 35 & 20 & 0.3 \\
850 & 850 & 850 & 25 & 20 & 45 & 25 & 0.5 \\
1000 & 1000 & 1000 & 30 & 25 & 55 & 28 & 0.6 \\
1100 & 1100 & 1100 & 40 & 30 & 70 & 32 & 0.7 \\
1200 & 1200 & 1200 & 45 & 40 & 85 & 36 & 0.8 \\
1250 & 1250 & 1250 & 50 & 45 & 95 & 43 & 0.9 \\
1300 & 1300 & 1300 & 55 & 50 & 105 & 47 & 1.0 \\
1400 & 1400 & 1400 & 60 & 55 & 115 & 53 & 1.2 \\
1500 & 1500 & 1500 & 70 & 65 & 135 & 58 & 1.4 \\
1600 & 1600 & 1600 & 75 & 70 & 145 & 63 & 1.5 \\
1650 & 1650 & 1650 & 80 & 85 & 165 & 69 & 1.7 \\
1750 & 1750 & 1750 & 90 & 95 & 185 & 75 & 1.9 \\
$\ldots$ & $\ldots$ & $\ldots$ & $\ldots$ & $\ldots$ & $\ldots$ & $\ldots$ & $\ldots$ \\
\hline
\end{tabular}

(2) The core function is chosen; the mapping relation between the input and output parameters is obtained through sample learning.

(3) The new parameters are input into the regression least squares support vector machine to carry out prediction of the hydraulic excavator performance.

(4) The new learning samples of the hydraulic excavator system are added to the regression least squares support vector machine; then the prediction ability of model can be improved.

The prediction effect of the least squares support vector machine can be judged by the root-mean-square error, which is expressed as follows [10]:

$$
E=\sqrt{\frac{1}{n} \sum_{i=1}^{n}\left(\frac{y_{i}-\bar{y}_{i}}{y_{i}}\right)^{2}} \times 100 \% .
$$

Through field test for the hydraulic excavator 100 group samples are obtained, and the former 60 groups of samples are used as performance predicting samples of the hydraulic excavator, and the other 40 groups of samples are used as verification samples of prediction model; the performance prediction simulation programmer of the hydraulic excavator is compiled by MATLAB software.

The input parameters of performance prediction model for the hydraulic excavator are listed as follows: rotating speed of engine $n_{I C E}$, the rotating speed of motor $n_{E M}$, rotating speed of the hydraulic pump $n_{P}$, the torque of the engine $T_{I C E}$, the torque of the motor $T_{E M}$, and the torque of the hydraulic pump $T_{P}$; the output parameters of the model are output power of the engine $N_{I C E}$ and the pilot controlling pressure of hydraulic control valve $P$, respectively; the part samples are shown in Table 1.

The performance predicting curve and actual measurement curve of output power for the engine are shown in Figure 1. As seen from Figure 1, the output power of the engine changes in the moment with time, and output power

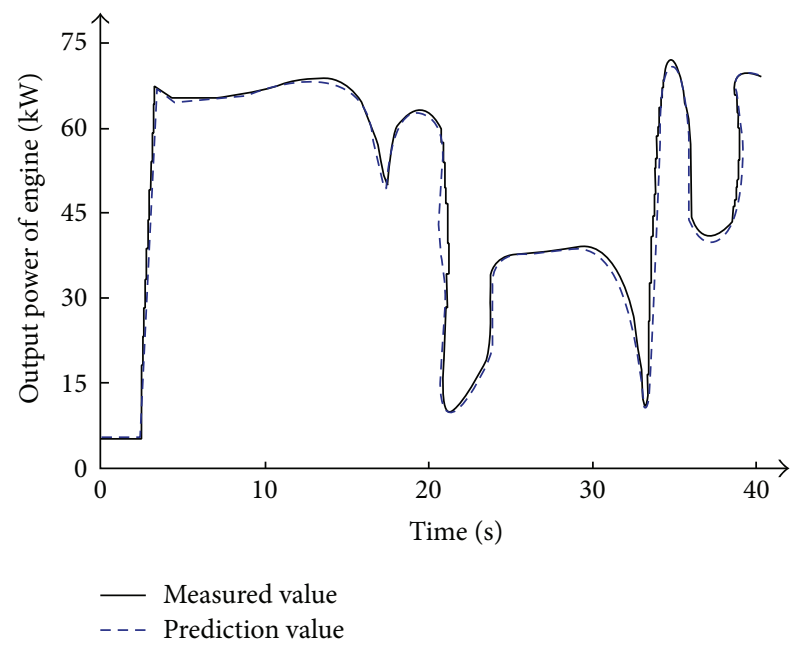

FIGURE 1: Performance predicting curve and measured curve of output power for engine.

TABLE 2: Output power prediction results of the hydraulic excavator based on different prediction model.

\begin{tabular}{|c|c|c|c|c|}
\hline \multirow[b]{2}{*}{ Time/s } & \multirow{2}{*}{$\begin{array}{c}\text { Measured output } \\
\text { power/kW }\end{array}$} & \multicolumn{3}{|c|}{ Prediction output power $/ \mathrm{kW}$} \\
\hline & & LS-SVM & $\begin{array}{l}\text { Traditional } \\
\text { SVM }\end{array}$ & $\begin{array}{c}\text { BP neutra } \\
\text { network }\end{array}$ \\
\hline 5 & 46 & 49 & 53 & 57 \\
\hline 10 & 64 & 66 & 69 & 73 \\
\hline 15 & 63 & 65 & 70 & 74 \\
\hline 20 & 49 & 52 & 58 & 61 \\
\hline 25 & 36 & 38 & 41 & 45 \\
\hline 30 & 38 & 40 & 45 & 52 \\
\hline 35 & 35 & 38 & 43 & 49 \\
\hline
\end{tabular}

changes irregularly; the predicting results agree with the actual measurements, and these results show that the least squares support vector machine based on regression has better prediction ability.

During the working process of the hydraulic excavator, the input parameter can be regulated based on the prediction results of the least squares support vector machine based on regression; then the hydraulic excavator can work steadily, and it can be in the optimal performance point; the working efficiency of the hydraulic excavator can be improved accordingly.

The output power prediction results of the hydraulic excavator from the regression least square support vector machine, traditional support vector machine, and BP neutral network are compared, which are shown in Table 2.

As seen from Table 2, the prediction results from the regression least support vector machine are closer to the measured value than those from tradition support vector machine and BP neutral network. The regression least support vector machine can obtain best performance prediction results of the hydraulic excavator. 


\section{Conclusions}

The least squares support vector machine based on regression is applied in the performance prediction of the hydraulic excavator, the model of the least squares support vector machine based on regression is established, the corresponding algorithm procedure is designed, and the performance prediction model of the hydraulic excavator is established. The performance prediction simulation is carried out, and results show that the regression least squares support vector machine has higher prediction precision, which can predict the changing rules of the performance for the hydraulic excavator and improve the working efficiency, which has wide application space.

\section{Conflict of Interests}

The author declares that there is no conflict of interests regarding the publication of this paper.

\section{References}

[1] M. Haga, W. Hiroshi, and K. Fujishima, "Digging control system for hydraulic excavator," Mechatronics, vol. 11, no. 6, pp. 665676, 2001.

[2] Z.-Y. Jia, J.-W. Ma, F.-J. Wang, and W. Liu, "Hybrid of simulated annealing and SVM for hydraulic valve characteristics prediction," Expert Systems with Applications, vol. 38, no. 7, pp. 80308036, 2011.

[3] Q. P. Ha, Q. H. Nguyen, D. C. Rye, and H. F. DurrantWhyte, "Impedance control of a hydraulically actuated robotic excavator," Automation in construction, vol. 9, no. 5, pp. 421-435, 2000.

[4] Y. Hong and C. W. W. Ng, "Base stability of multi-propped excavations in soft clay subjected to hydraulic uplift," Canadian Geotechnical Journal, vol. 50, no. 2, pp. 153-164, 2013.

[5] J. Jiang, C. Song, and L. Bao, "ForwardGene selection algorithm based on least squares support vector machine," Journal of Bionanoscience, vol. 7, no. 3, pp. 307-312, 2013.

[6] M.-Y. Ye and X.-D. Wang, "Chaotic time series prediction using least squares support vector machines," Chinese Physics, vol. 13, no. 4, pp. 454-458, 2004.

[7] S. Swaddiwudhipong, K. K. Tho, Z. S. Liu, J. Hua, and N. S. B. Ooi, "Material characterization via least squares support vector machines," Modelling and Simulation in Materials Science and Engineering, vol. 13, no. 6, pp. 993-1004, 2005.

[8] Y. Wan, "Pump performance analysis based on least squares support vector machine," Transactions of the Chinese Society of Agricultural Engineering, vol. 25, no. 8, pp. 115-118, 2009.

[9] X. Wang, X. Tian, and Y. Cheng, "Value approximation with least squares support vector machine in reinforcement learning system," Journal of Computational and Theoretical Nanoscience, vol. 4, no. 7-8, pp. 1290-1294, 2007.

[10] K. Huang, H. J. Wang, H. R. Xu, J. P. Wang, and Y. B. Ying, "NIR spectroscopy based on least square support vector machines for quality prediction of tomato juice," Spectroscopy and Spectral Analysis, vol. 29, no. 4, pp. 931-934, 2009. 

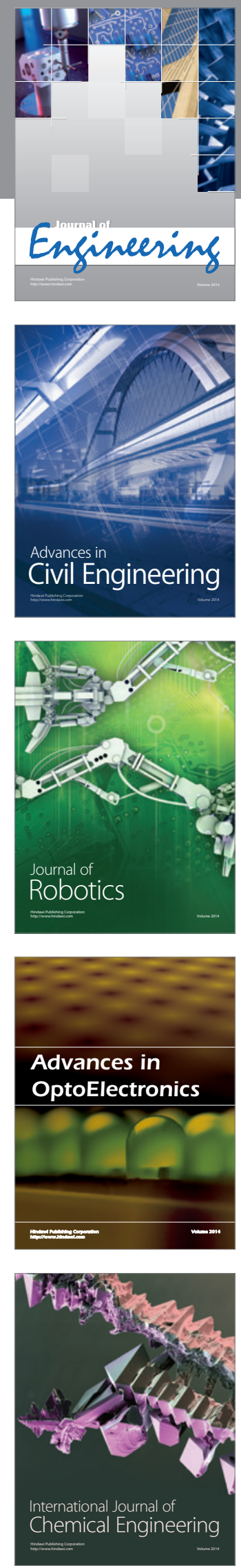

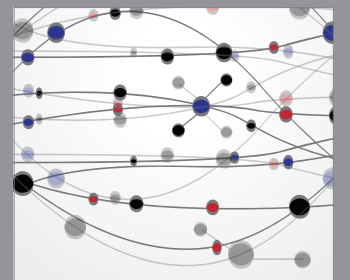

The Scientific World Journal
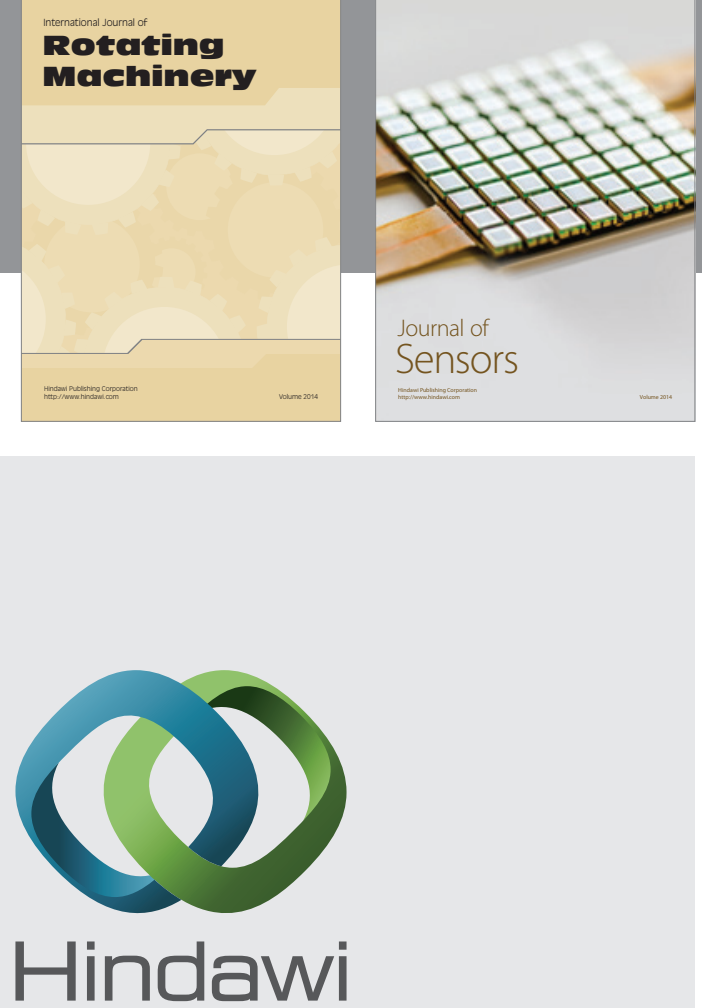

Submit your manuscripts at http://www.hindawi.com
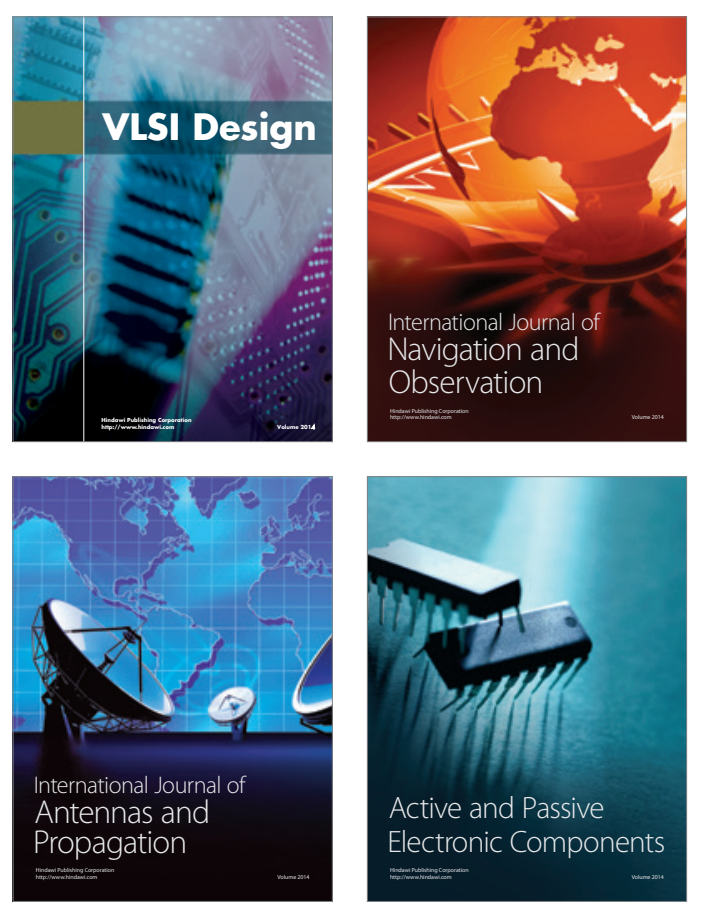
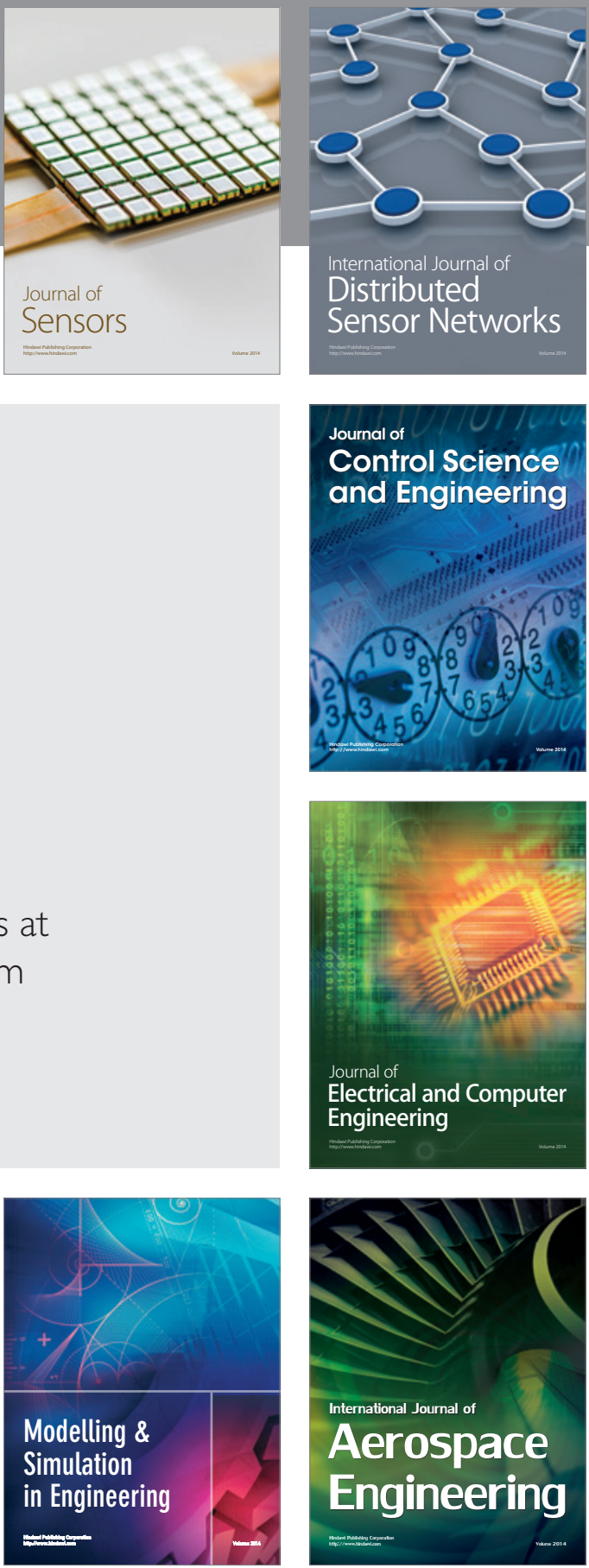

Journal of

Control Science

and Engineering
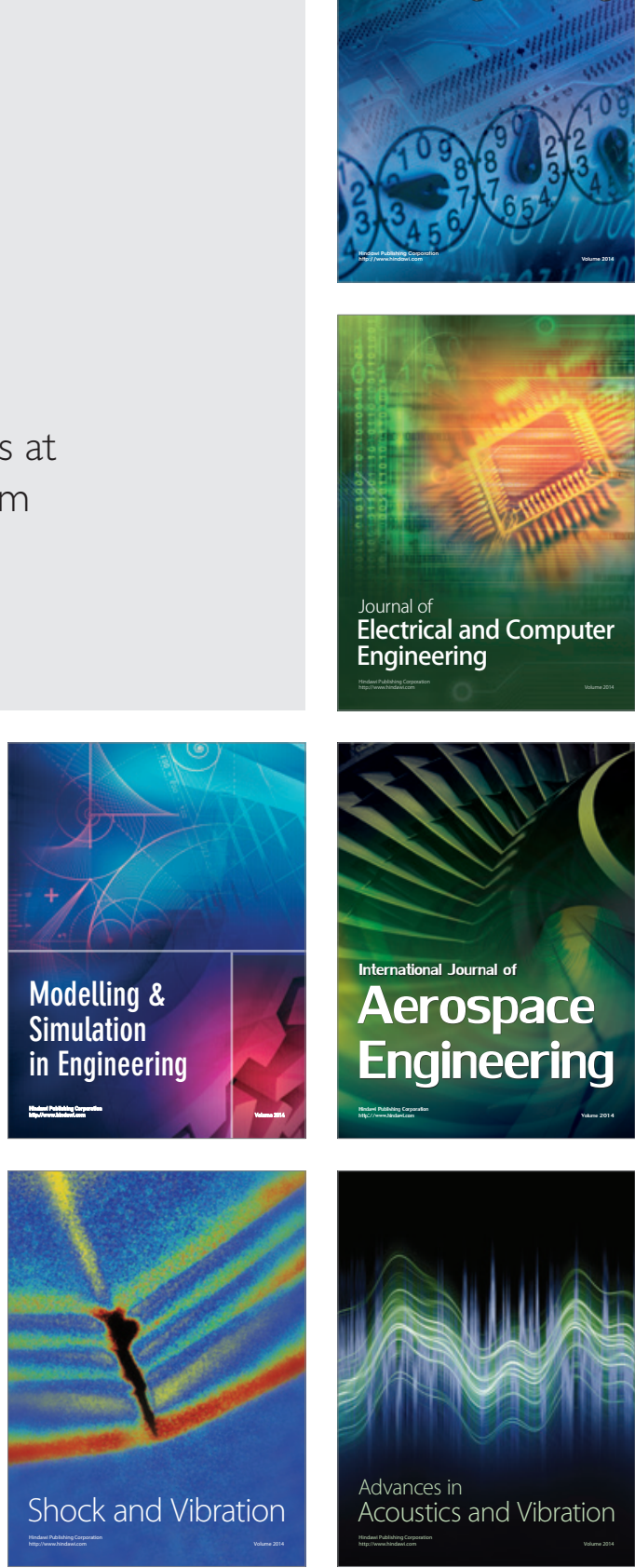